\title{
Análise de um infográfico à luz da Teoria da Mesclagem Conceptual e da Semiótica Plástica greimasiana: a interdisciplinaridade a serviço da compreensão de um texto sincrético
}

\author{
Aline Nardes dos Santos *
}

\begin{abstract}
Resumo
Este trabalho tem por objetivo verificar a existência de pontos de correspondência entre o aparato teórico da Teoria da Mesclagem Conceptual e as categorias de análise da Semiótica Plástica ou Visual, de modo a compreender a construção de significados em um infográfico, cujo tema é a dificuldade de acesso ao aborto legal por mulheres pobres no contexto estadunidense. Por infográfico, entende-se um gênero sincrético que conjunge informações visuais e escritas, organizadas de modo a consolidar uma unidade de comunicação autônoma. De modo geral, a análise empregada é qualitativa, compreendendo identificação das mesclagens conceptuais emergentes e verificação dos elementos visuais do infográfico que se relacionam a essas mesclagens a partir das categorias topológica, eidética e cromática. Como os resultados indicam, foi possível enriquecer a descrição das mesclagens conceptuais a partir do emprego das categorias plásticas greimasianas, visto que a própria mesclagem que estrutura o infográfico dá-se por meio da conjunção entre texto e imagem.

Palavras-chave: Teoria da Mesclagem Conceptual. Semiótica Plástica greimasiana. Infográfico. Multimodalidade. Aborto.
\end{abstract}

* Universidade do Vale do Rio dos Sinos (Unisinos). Doutoranda em Linguística Aplicada. 


\section{Introdução}

As teorias da Linguística Cognitiva têm se mostrado bastante profícuas para análises de cunho textual-discursivo (ZIEM, 2014; HART, 2010; SEGUNDO, 2014). Nesse âmbito, destacam-se propostas analíticas voltadas a textos multimodais e bases de dados transmidiáticas (FERNANDES; JÜRGENS, 2009), bem como abordagens que analisam aspectos gestuais da linguagem, principalmente para descrever línguas de sinais (FERREIRA, 2014). Dentre as teorias mais utilizadas nessas propostas interdisciplinares, está a Teoria da Mesclagem Conceptual (FAUCONNIER; TURNER, 2002), que preconiza a construção dinâmica do significado em contexto discursivo, a partir de estruturas conceptuais que se constroem online - no curso da comunicação -, as quais mesclam domínios diferentes conforme os propósitos dos falantes.

Este trabalho tem por objetivo aproximar o aparato teórico da Teoria da Mesclagem Conceptual às categorias de análise da Semiótica Plástica ou Visual (GREIMAS, 2004), de modo a compreender a construção de significados em um infográfico, cujo tema é a dificuldade de acesso ao aborto legal por mulheres pobres no contexto norte-americano. Por infográfico, entendemos um gênero sincrético que conjunge informações visuais e escritas, organizadas de modo a consolidar uma unidade de comunicação autônoma (CARVALHO; ARAGÃO, 2012). Dessa forma, acreditamos que uma análise das mesclagens conceptuais que emergem desse infográfico pode ser enriquecida por uma descrição das categorias plásticas que estruturam esse texto sincrético.

De modo a delinear nosso percurso analítico, organizamos o texto da seguinte maneira: na primeira seção, introduzimos a Teoria da Mesclagem Conceptual no contexto da Linguística Cognitiva; na seção seguinte, abordamos as categorias plásticas, provenientes da Semiótica Visual, que serão integradas à nossa análise. Na seção 3, detalhamos o objeto de pesquisa e elencamos as etapas metodológicas empregadas para, na seção 4, trazermos a análise interdisciplinar do infográfico. Por fim, a última seção traz as considerações finais, além das limitações do trabalho e das perspectivas de investigações futuras.

\section{A "salada mista" do significado: mesclagens conceptuais}

As teorias que compõem o empreendimento da Linguística Cognitiva consideram que o significado deve ser o cerne da pesquisa linguística, visto que 
revela o modo como funcionam os processos cognitivos que nos permitem ler o mundo e expressar nosso ponto de vista por meio da linguagem (KÖVECSES, 2006). Dentre os aspectos principais que embasam essa perspectiva, está o caráter imaginativo do significado: para teorias linguístico-cognitivas, a imaginação é primordial em processos de construção conceptual, desempenhando "[...] um papel central na constituição da racionalidade." (JOHNSON, 1987, p. ix) ${ }^{1}$. Assim, essa corrente linguística parte de uma visão experiencialista - portanto, não objetivista ${ }^{2}$ - do significado, defendendo que

A razão [...] resulta da natureza de nossos cérebros, corpos, e experiência corporal. [...] Os mesmos mecanismos neurais e cognitivos que nos permitem perceber e nos mover também criam nossos sistemas conceptuais e modos de raciocinar. [...] Em suma, a razão não é, de nenhuma forma, um traço transcendental do universo ou da mente descorporificada. Em vez disso, é moldada crucialmente pelas peculiaridades de nossos corpos humanos, pelos detalhes extraordinários da estrutura neural de nossos cérebros, e pelas especificidades de nosso funcionamento diário no mundo. ${ }^{3}$

Dessa forma, a Linguística Cognitiva parte do pressuposto de que processos imaginativos revelam como a construção do significado depende não apenas de operações cognitivas individuais, mas também de construções sociocognitivas que refletem a criatividade do falante ao manipular a linguagem. Assim, o papel ativo dos sujeitos é constantemente evidenciado no discurso, inclusive a partir de sua habilidade em integrar diferentes estruturas conceptuais para expressar um significado.

1 No original: "[...] a central role in the constitution of rationality". (JOHNSON, 1987, p. ix).

2 Por objetivismo, entendemos o conjunto de abordagens filosóficas e linguísticas que defendem a existência de um mundo objetivo e independente da subjetividade dos falantes. Para essa corrente, o mundo é "[...] objetivamente construído, isto é, independente do entendimento de qualquer organismo. [...] Na visão objetivista, todo o pensamento racional envolve a manipulação de símbolos abstratos aos quais é dado significado apenas por meio de correspondências convencionais com coisas no mundo externo. (LAKOFF, 1990, p. xii, grifo do autor). - No original: "[...] objectively construed, that is, independent of the understanding of any organism. [...] On the objectivist view, all rational thought involves the manipulation of abstract symbols which are given meaning only via conventional correspondences with things in the external world".

3 No original: "Reason [...] arises from the nature of our brains, bodies, and bodily experience. [...] The same neural and cognitive mechanisms that allow us to perceive and move around also create our conceptual systems and modes of reason. [...] In summary, reason is not, in any way, a transcendent feature of the universe or of disembodied mind. Instead, it is shaped crucially by the peculiarities of our human bodies, by the remarkable details of the neural structure of our brains, and by the specifics of our everyday functioning in the world." (LAKOFF; JOHNSON, 1999, p. 4). 
A exemplo disso, consideremos o subtítulo desta seção: a "salada mista" do significado. Para expressar a heterogeneidade desse fenômeno cognitivodiscursivo, realizamos uma integração conceptual entre "significado" e "salada mista", mesclando parcialmente o conteúdo conceptual desses dois domínios - o primeiro mais abstrato e o segundo, mais concreto. Conforme a Teoria da Mesclagem Conceptual, esse é um exemplo de integração entre domínios diferentes, que pode ser descrito a partir de quatro espaços mentais, ou seja, quatro "pacotes de conteúdo conceptual temporários e limitados, configurados para auxiliar na compreensão [...] em situações particulares". (CRUSE, 2006, p. 104). ${ }^{4}$

O primeiro espaço mental, também denominado espaço genérico, "representa o lugar das informações comuns sobre os domínios a serem correlacionados". (CREPALDE, 2014, p. 59). Nesse caso específico, temos a correlação entre um alimento (salada) e um fenômeno (o significado), por meio da heterogeneidade que os caracteriza. Os espaços 2 e 3 são elaborados a partir das especificidades dos dois domínios mesclados, elencando-se as propriedades comuns a ambos os espaços. Por fim, o quarto espaço, ou espaço da mescla, traz o elemento resultante dessa fusão entre domínios. A Figura a seguir detalha essa descrição:

\section{Figura 1: Exemplo de mesclagem}

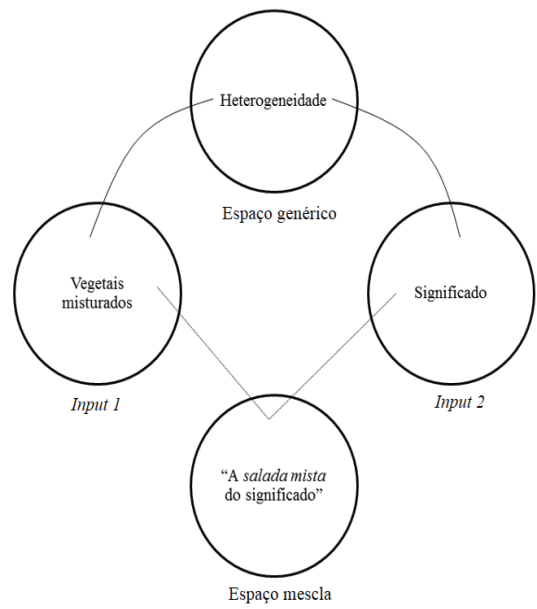

Fonte: elaborada pela autora, 2016.

4 No original: "[...] are temporary, limited packages of conceptual content set up to assist understanding [...] on particular occasions." (CRUSE, 2006, p. 104). 
Com esse aparato teórico-metodológico, a teoria da Mesclagem Conceptual "visa a fornecer um modelo geral cognitivo para a criação de significado e para o modo como novos conceitos emergem." (BIRDSELL, 2012, p. 85). ${ }^{5}$ Como explicam Kövecses (2006), e Salomão (2009), essa abordagem é produtiva para se analisar processos de criação sintática e lexical, bem como para explicar o modo como falantes elaboram metáforas. Nesse sentido, essa abordagem se aproxima consideravelmente da Teoria da Metáfora Conceptual (LAKOFF, 1980), contudo dela se diferencia por trabalhar não apenas com dois domínios principais - no caso do exemplo, seriam os domínios do "significado" e da "salada" -, mas também com o espaço genérico e o espaço da mescla, elaborando "redes de integração conceptual" (TURNER, 2007, p. 378) que descrevem o significado como processo construído dinamicamente.

A próxima seção trata das categorias da semiótica plástica que serão integradas em nossa análise.

\section{Semiótica plástica: categorias topológicas, eidéticas e cromáticas}

Segundo Morato (2008), a semiótica plástica ou visual tem como marco a semiótica greimasiana. Como explica Oliveira (2014), "É o próprio Greimas que se debruça sobre a figuratividade do visual para teorizar a sua relação com a dimensão plástica, fundamento esse que seria largamente homologado pelos estudos dos semioticistas nas décadas seguintes [...]”. (OLIVEIRA, 2014, p.15).

No texto intitulado "Semiótica figurativa e semiótica plástica", Greimas define semiótica visual a partir de seu objeto, cujo suporte é sempre planar. Assim, a semiótica possui “caráter construído, artificial” (GREIMAS, 2004, p. 76), pois dá conta de manifestações que representam ou imitam o mundo natural, tais como fotografias e pinturas. Assim como na Linguística Cognitiva, a visão de mundo greimasiana não implica um mundo objetivo: os significados criados por meio das imagens planares fazem parte "da leitura humana do mundo e não do próprio mundo". (GREIMAS, 2004, p. 79, grifo do autor). Portanto, as representações do mundo, que constituem objetos da semiótica visual, também são construídas intersubjetivamente, dependendo do reconhecimento de determinada comunidade: toda e qualquer representação elaborada por um enunciador depende do "crivo de leitura" dos enunciatários.

5 No original: aims to provide a general cognitive model for meaning-making and for how novel concepts emerge. (BIRDSELL, 2012, p. 85). 
Ainda segundo o semioticista (2004), a análise de significantes implica processos de decomposição e integração, conforme for estruturada a leitura do analista. Esse modo de olhar o objeto é diferente daquele que é geralmente empregado em análises de textos escritos - como explica o autor, na escrita, a leitura é sempre linear e unidimensional. Já na análise de objetos plásticos, para ele,

Pouco importa que a análise comece pelo reconhecimento de traços mínimos, cuja combinatória produz as figuras e os formantes plásticos, ou que procure apreender, em primeiro lugar, "blocos de significação" ou "dispositivos", que são unidades de dimensões mais amplas, decomponíveis. Num caso como noutro, trata-se de encaminhamentos de segmentação que repousam, em boa parte, sobre apreensões intuitivas das quais é preciso, em primeiro lugar, explicitar os procedimentos e formular regras de uso generalizado. (GREIMAS, 2004, p. 85).

Nesse texto seminal, encontramos as categorias de análise que permitem a descrição de significantes plásticos, as quais "constituem o nível fundamental da forma do significante" (GREIMAS, 2004, p. 88). A primeira é o conjunto de "categorias topológicas", que traçam eixos e delimitam regiões na superfície planar. Já as "categorias plásticas" compreendem dois tipos: as "eidéticas", concernentes às formas que podem ser identificadas e contrastadas; e as categorias "cromáticas", que se referem à análise de cores e tonalidades empregadas no objeto de análise. O quadro a seguir traz exemplos para cada uma das categorias, tomando também como base as análises encontradas em Pietroforte (2004) e Souza (2012) - além dos exemplos dados pelo próprio Greimas (2004).

Quadro 1: categorias de análise de significantes plásticos

\begin{tabular}{|c|c|}
\hline Categorias & Exemplos \\
\hline Topológicas & $\begin{array}{c}\text { "superior" vs. "inferior" } \\
\text { "direito" vs. "esquerdo" }\end{array}$ \\
\hline Plásticas - eidéticas & "menor" vs. "maior" \\
"uniforme" vs. "multiforme"
\end{tabular}

Fontes: Greimas (2004), Pietroforte (2004); Souza, (2012). 
É importante situar a semiótica plástica quanto aos chamados "planos de conteúdo" e de "expressão" - disjunção oriunda dos trabalhos de Hjelmslev (1975). Segundo Souza (2012), o "plano de expressão" concerne às formas de manifestação da linguagem - exemplos dados por Pietroforte (2007) são os planos fonológico e fotográfico. Já o "plano do conteúdo" "é aquele em que a significação se relaciona a diferentes culturas, e no qual se organizam e se encadeiam ideias e narrativas". (SOUZA, 2012, p. 119). Nesse âmbito, para Greimas (2004), a semiótica plástica é semissimbólica, porque acarreta correspondências entre "categorias" do plano de expressão e do plano do conteúdo - e não entre "elementos" isolados de cada plano, como ocorre em semióticas simbólicas. Floch (1985 apud SOUZA, 2012) exemplifica esse último caso com a linguagem formal do semáforo, em que cada elemento do plano da expressão corresponde a um único elemento do plano do conteúdo.

No que se refere às bases epistemológicas da semiótica visual greimasiana, importa ressaltar que

O ponto de partida da teoria semântica de Greimas (1966:19) é sua definição de estrutura, na qual se dá prioridade às relações em vez dos elementos, já que somente as diferenças (que são relações) entre elementos constituem uma estrutura. As relações elementares do mundo semântico de Greimas são relações de oposição: o mundo se estrutura para nós na forma de diferenças e oposições. (NOTH, 1996, p. 151).

Assim, as relações opositivas podem ser sistematizadas por meio do quadrado semiótico, o qual "compõe o nível metalinguístico da Semiótica” (SOUZA, 2012, p. 126): 


\section{Figura 2: quadrado semiótico}

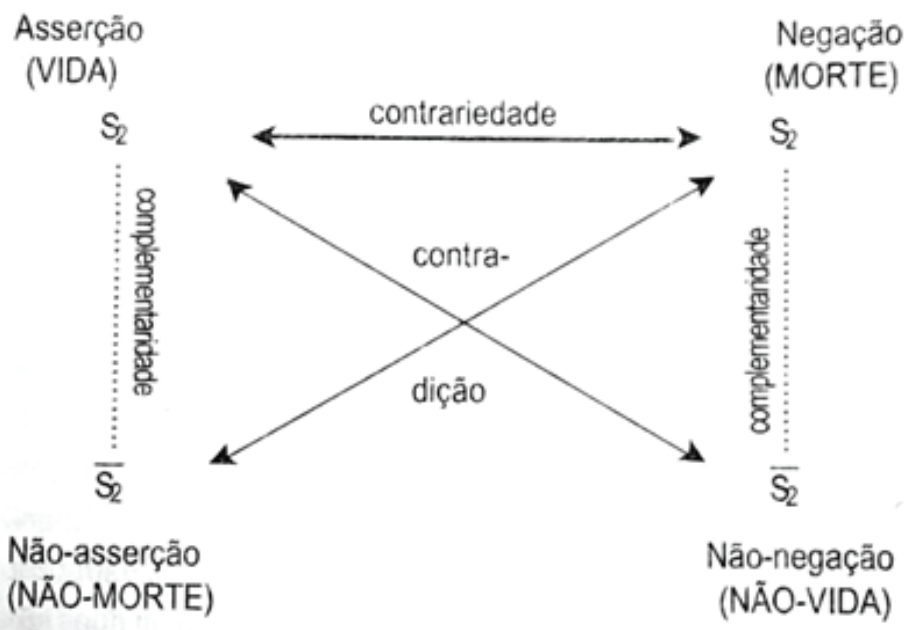

Fonte: NOTH, 1996, p. 155.

A seção seguinte detalha o objeto de estudo e os procedimentos metodológicos empregados na análise.

\section{Metodologia}

Neste trabalho, o objeto de investigação é um infográfico relacionado à temática do aborto no contexto americano (ver Figura 3) - trata-se, portanto, de um estudo de caso. O motivo principal de nossa escolha é o fato de estudarmos a temática do aborto desde nossa dissertação de mestrado (SANTOS, 2016), o que nos motivou a dar continuidade às investigações, ampliando o escopo de análise e buscando perspectivas interdisciplinares que propiciassem novos olhares sobre a temática.

Ao encontro disso, a escolha de um infográfico, como mostra o estudo de Souza (2012), implica a necessidade de um olhar aberto a diferentes abordagens analíticas, visto que se trata de um texto sincrético, o qual resulta na presença simultânea de texto escrito e imagens na composição de sua unidade. Esse conceito geral de infográfico também nos leva a considerar que o exemplar escolhido apresenta um nível suficiente de prototipicidade (PINTO, 2010), ou seja, possui uma estrutura representativa no que concerne à organização do infográfico como unidade sincrética e autônoma. 
Análise de um infográfico à luz da Teoria da Mesclagem Conceptual e da Semiótica Plástica greimasiana: a interdisciplinaridade a serviço da compreensão de um texto sincrético

\section{Figura 3: Infográfico analisado}

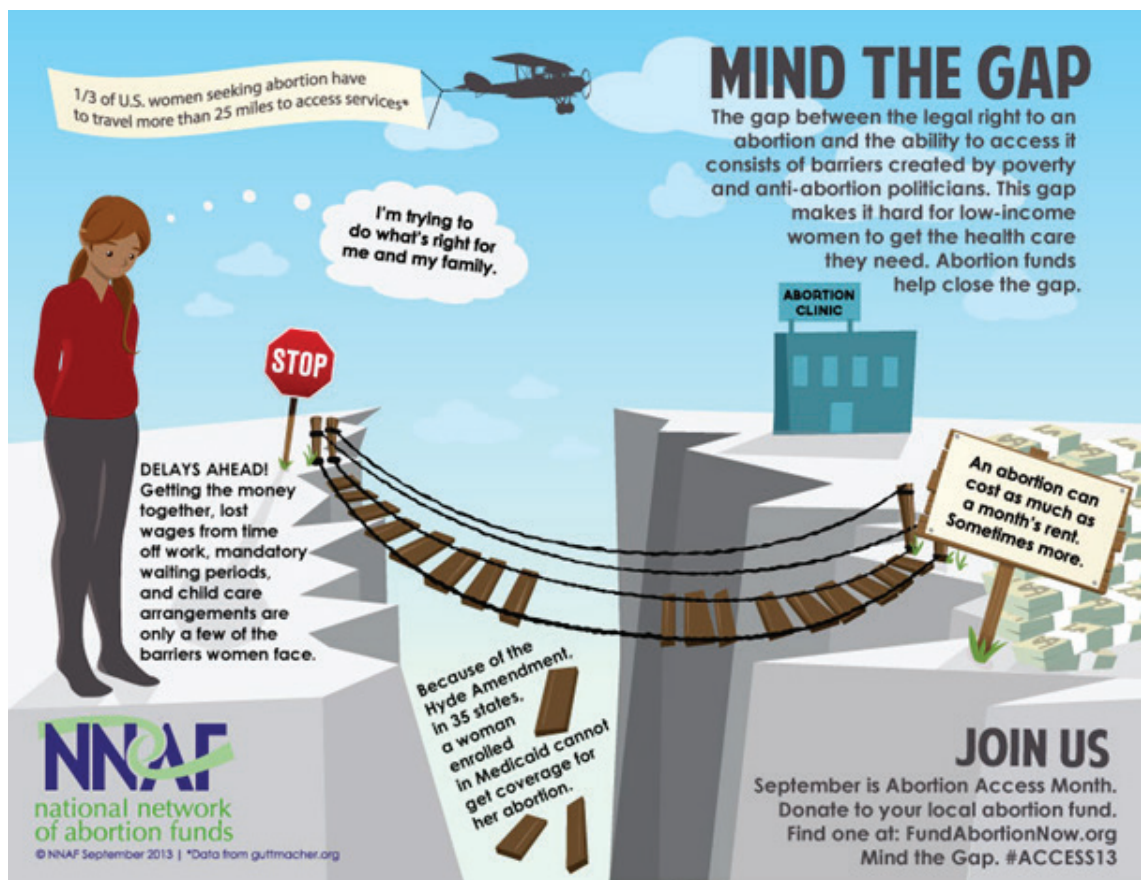

Fonte: National Network of Abortion Funds, 2013.

O infográfico analisado, intitulado "Mind the gap", foi produzido pela National Network of Abortion Funds (NNAF), com sede em Boston (EUA). Essa rede conecta grupos de pessoas que querem ajudar mulheres pobres a realizar um aborto, visto que, embora o ato não seja mais enquadrado como crime em nenhum estado americano, mulheres sem condições financeiras e que moram longe de clínicas especializadas enfrentam muitas dificuldades ao buscar atendimento. O infográfico produzido tem o propósito de angariar mais fundos para auxiliar mulheres pobres, trazendo dados que justificam essa busca por apoio.

A análise empregada neste trabalho é qualitativa, abrangendo as seguintes etapas: (a) leitura do infográfico "Mind the gap" e identificação das mesclagens conceptuais emergentes; (b) sistematização das mesclagens encontradas e criação uma rede de integração conceptual - conforme estrutura da Figura 1; (c) identificação dos elementos visuais do infográfico que se relacionam a essas mesclagens a partir das categorias "topológica", "eidética" e "cromática" conforme Quadro 1; (d) integração e síntese das análises realizadas, por meio de 
uma ilustração unificada que englobe e inter-relacione elementos das mesclagens e das categorias plásticas.

\section{Análise do infográfico}

Ao analisar o infográfico sob a ótica das mesclagens conceptuais, percebemos que o texto é construído a partir de uma integração central, que tem como base a polissemia do termo "gap": segundo o dicionário Merriam Webster, a palavra pode concernir tanto a uma lacuna entre duas coisas ou pessoas, quanto a aspectos mais específicos, ligados a certos tipos de relevo ${ }^{6}$. O termo se insere na conhecida expressão "mind the gap" (em tradução livre, "cuidado com o vão"), utilizada em avisos de trens para alertar os passageiros quanto à lacuna existente entre o trem e a plataforma. No entanto, o "vão" referido no texto concerne à lacuna entre o aborto legal e a facilidade em acessá-lo, principalmente por mulheres pobres, conforme mostra o excerto reproduzido a seguir: "A lacuna entre o direito legal a um aborto e a habilidade de acessá-lo consiste em barreiras criadas pela pobreza e por políticos antiaborto. Essa lacuna torna difícil, para mulheres pobres, obter o serviço de saúde de que necessitam. Fundos de aborto ajudam a fechar essa lacuna."7

A partir desse excerto e da ilustração do infográfico, que mostra um vão físico separando a jovem mulher da clínica de aborto, podemos perceber que o domínio do "relevo" é utilizado para construir uma ideia mais complexa, do domínio do "aborto", referente à lacuna entre acesso legal e acesso real a esse procedimento. Quanto ao relevo, o infográfico ilustra uma lacuna entre planos, ou ravina, cujo ponto de passagem está deteriorado. Em termos de mesclagem conceptual, podemos descrever o espaço mental genérico como uma lacuna entre dois elementos. Já os inputs 1 e 2 concernem, respectivamente, aos domínios do aborto e do relevo. Por fim, o espaço da mescla mostra a fusão entre essas duas estruturas conceptuais:

6 Algumas definições de "gap": "1) a: a break in a barrier (as a wall, hedge, or line of military defense); b: an assailable position. 2) a: a mountain pass b: ravine 3) spark gap 4) a: a separation in space; b: an incomplete or deficient area <a gap in her knowledge>". (GAP... [2016?]).

7 No original: "The gap between the legal right to an abortion and the ability to access it consists of barriers created by poverty and anti-abortion politicians. This gap makes it hard for low-income women to get the health care they need. Abortion funds help close the gap." (NATIONAL..., 2013). 
Figura 4: esquematização da mesclagem conceptual (parte 1)

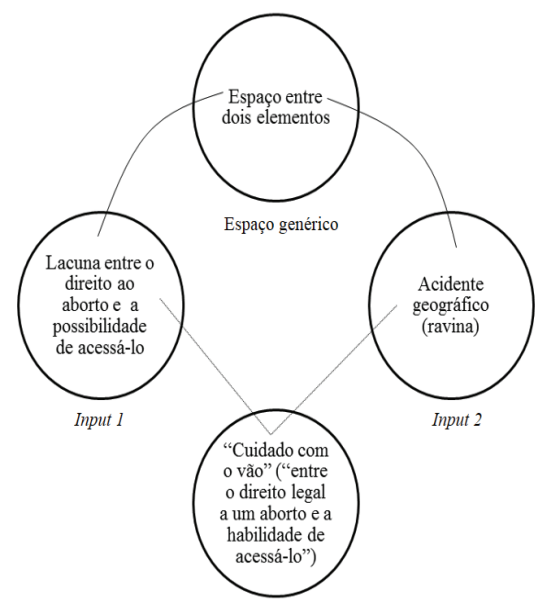

Fonte: elaborada pela autora, 2016.

Mais especificamente, podemos relacionar os elementos dos inputs 1 e 2 que são selecionados para dar origem à fusão do espaço mescla: no texto de apoio (i) e na ilustração do relevo (ii), temos os seguintes elementos: (i) mulher pobre/ (ii) mulher (jovem) pobre, (i) barreiras de acesso ao aborto/(ii) ponte deteriorada, (i) falta de acesso ao dinheiro e à clínica/(ii) dinheiro e clínica do lado oposto da ravina. Essas inter-relações são detalhadas na rede de integração conceptual a seguir:

Figura 5: esquematização da mesclagem conceptual (parte 2)

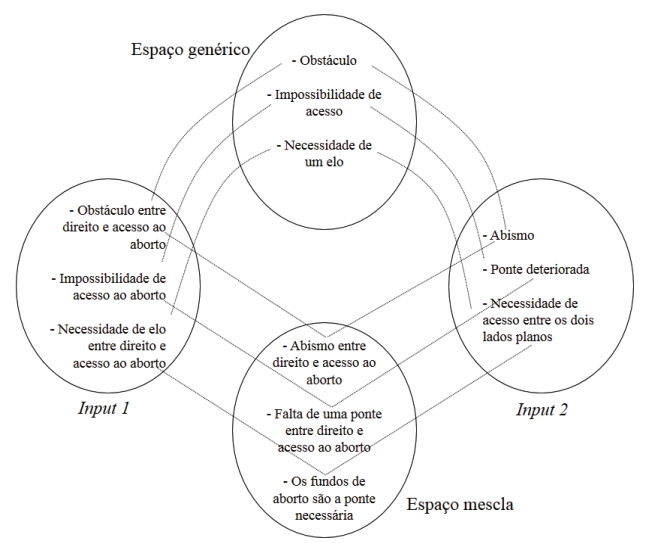

Fonte: elaborada pela autora, 2016. 
De uma perspectiva semiótica greimasiana, podemos considerar que o jogo de oposições se realiza por meio da asserção principal na qual se funda o infográfico - a de que, no contexto dos EUA, "mulheres pobres têm dificuldade em acessar clínicas para realizar aborto legal". Desse modo, embora se possa pensar que a legalização do aborto resultaria em acesso facilitado a esse serviço, o texto mostra que isso não ocorre: mulheres sem condições financeiras enfrentam barreiras como juntar o dinheiro, enfrentar filas de espera e providenciar cuidadores para seus filhos. Logo, no plano de conteúdo, a categoria semântica que parece emergir do infográfico é "acesso" vs. "falta de acesso". Ainda vale observar que essas relações podem ser interpretadas em termos de figurativização e tematização (GREIMAS; COURTÉS, 1980): o distanciamento entre o direito e o acesso ao aborto é tematizado como problema social, sendo figurativizado por meio do abismo entre os dois planos que constituem a ravina. A seguir, abordamos as categorias do plano de expressão que se relacionam a essa oposição.

Como explica Pietroforte (2007), as categorias topológicas permitem que se observe como ocorre a semantização do espaço a partir dos contrastes encontrados no plano de conteúdo. No infográfico analisado, verificamos que a mulher em busca do aborto e o espaço por ela almejado - onde se encontram a clínica e o dinheiro - estão distribuídos de acordo com a categoria plástica "esquerdo" vs. "direito". Em complementaridade a essa oposição, também é possível observar a categoria "central" vs. "periférico", que focaliza o vão entre as planícies, ou ravina, a qual reflete a inacessibilidade de mulher pobre ao aborto.

\section{Quadro 2: categorias topológicas}

\begin{tabular}{|c|c|}
\hline Planos & Categorias \\
\hline Plano de expressão & Topológicas: \\
& "esquerdo" vs. "direito" \\
& "central" vs. "periférico" \\
\hline Plano de conteúdo & "falta de acesso" vs. "acesso" \\
\hline
\end{tabular}

Fonte: elaborada pela autora, 2016.

No que se refere às categorias eidéticas, o texto sugere a escolha de "retilíneo" vs. "curvilíneo": as divisões retilíneas sustentam o distanciamento rígido entre os dois polos separados pelo relevo, enquanto as formas curvilíneas, manifestas na 
ponte deteriorada e na faixa carregada pelo aeroplano no nível superior, remetem à ligação entre os dois lados, mesmo que de maneira precária. Também destacamos a categoria "dilatação" vs. "contração" - o que vai ao encontro da categoria topológica "central" vs. "periférico" -, dando ênfase ao abismo que separa a mulher do acesso ao serviço de saúde adequado para realizar o aborto, de modo que os dois lados contrastados ocupem, assim, um espaço menor na imagem.

Quadro 3: categorias eidéticas

\begin{tabular}{|c|c|}
\hline Planos & Categorias \\
\hline Plano de expressão & Eidéticas: \\
& "retilíneo" vs. "curvilíneo" \\
& "dilatação" vs. "contração" \\
\hline Plano de conteúdo & "falta de acesso" vs. "acesso" \\
\hline
\end{tabular}

Fonte: elaborada pela autora, 2016.

Quanto às cores do infográfico, a categoria plástica "escuro" vs. "claro" parecenos adequada para descrever a relação entre o centro da imagem, dominado pela ravina, cujos tons escuros enfatizam a profundidade do vão. Além disso, consideramos pertinente enfatizar a categoria "saturado" vs. "insaturado", que se refere à placa de "pare" e à blusa da jovem, ambas vermelhas - tons saturados -, e à clínica de aborto em azul, no lado oposto - tom insaturado. Para corroborar a existência dessa categoria, vale trazer as reflexões de Dondis ${ }^{8}$ (2007, p. 66 apud SOUZA, 2012) acerca dos efeitos causados pela escolha de cores mais ou menos saturadas:

A cor saturada é simples, quase primitiva, e sempre foi a preferida pelos artistas populares e pelas crianças. Não apresenta complicações, e é explícita e inequívoca; compõe-se dos matizes primários e secundários. As cores menos saturadas levam a uma neutralidade cromática, e até mesmo à ausência de cor, sendo sutis e repousantes. Quanto mais intensa ou saturada for a coloração de um objeto ou acontecimento visual, mais carregado estará de expressão e emoção. Os resultados informacionais, na opção por uma cor saturada ou neutralizada, fundamentam a escolha em termos de intenção. (DONDIS, 2007 apud SOUZA, 2012, p.135).

8 Dondis, designer e professora de comunicação, estuda os elementos que constituem a comunicação visual por meio de uma exploração minuciosa de cada um dos eixos necessários ao alfabetismo visual - um deles é o das cores. Para a autora, “A cor não apenas tem um significado universalmente compartilhado através da experiência, como também um valor informativo específico, que se dá através dos significados simbólicos a ela vinculados.” (DONDIS, 1997, p. 69). 
Essa passagem leva-nos a refletir não apenas sobre o azul "repousante" da clínica de aborto ilustrada, ou sobre o uso predominante de vermelho, em nossa cultura, para destacar placas de proibição: como Dondis explica, cores mais saturadas e intensas, como a vermelha, são carregadas de expressão e emoção. Assim, o uso do vermelho apenas do lado esquerdo enfatiza tanto os aspectos emocionais ligados à inacessibilidade ao aborto - que também se refletem na postura e no semblante da jovem ilustrada - quanto a expressividade dos obstáculos impostos à mulher. Desse modo, tais aspectos cromáticos apontam para a intransponibilidade das barreiras ocasionadas pela pobreza e por manobras políticas antiaborto, corroborando a asserção principal que embasa o infográfico.

\section{Quadro 4: categorias cromáticas}

\begin{tabular}{|c|c|}
\hline Planos & Categorias \\
\hline Plano de expressão & Cromáticas: \\
& "escuro" vs. "claro" \\
& "saturado" vs. "insaturado" \\
\hline Plano de conteúdo & "falta de acesso" vs. "acesso" \\
\hline
\end{tabular}

Fonte: elaborada pela autora, 2016.

A figura a seguir objetiva mostrar como as duas contrapartes analíticas empregadas neste trabalho se complementam, visto que apontam para diferentes efeitos de sentido que reforçam os mesmos propósitos da organização NNAF ao produzir esse gênero. Mais especificamente, acreditamos que as categorias do plano de expressão permitem compreendermos como se estrutura o espaço mental relativo ao domínio do relevo, concretizado na ilustração, de modo que a categoria semântica "acesso" vs. "falta de acesso" repercuta na estrutura do espaço da mescla. Nesse sentido, é importante considerarmos que o domínio do relevo resulta em uma construção de um espaço mental contrafactual, a partir do espaço da "realidade", em que mulheres não têm acesso ao aborto legal. Assim, a convergência entre a Semiótica Plástica e a teoria de Fauconnier e Turner permite considerarmos as informações não linguísticas de textos sincréticos como possíveis construtores de espaços mentais, aspecto que contribuiria para a ampliação do escopo analítico dessa abordagem linguístico-cognitiva. Ao encontro disso, a Semiótica Visual concebe as construções contrafactuais a partir das relações de oposição: "o que temos é um delineamento do que é real, do ponto da comprovação, de um lado com 

greimasiana: a interdisciplinaridade a serviço da compreensão de um texto sincrético

os eventos sabidamente (ou assumidos como) pertencentes ao mundo empírico, de outro lado com aqueles sabidamente (ou assumidos como) não pertencentes a ele." (PIASSI, 2012, p. 93-94). No caso do infográfico Mind the Gap, a figurativização do relevo pode ser considerada como a construção não empírica que embasa os contrastes semióticos efetivados nesse texto multimodal:

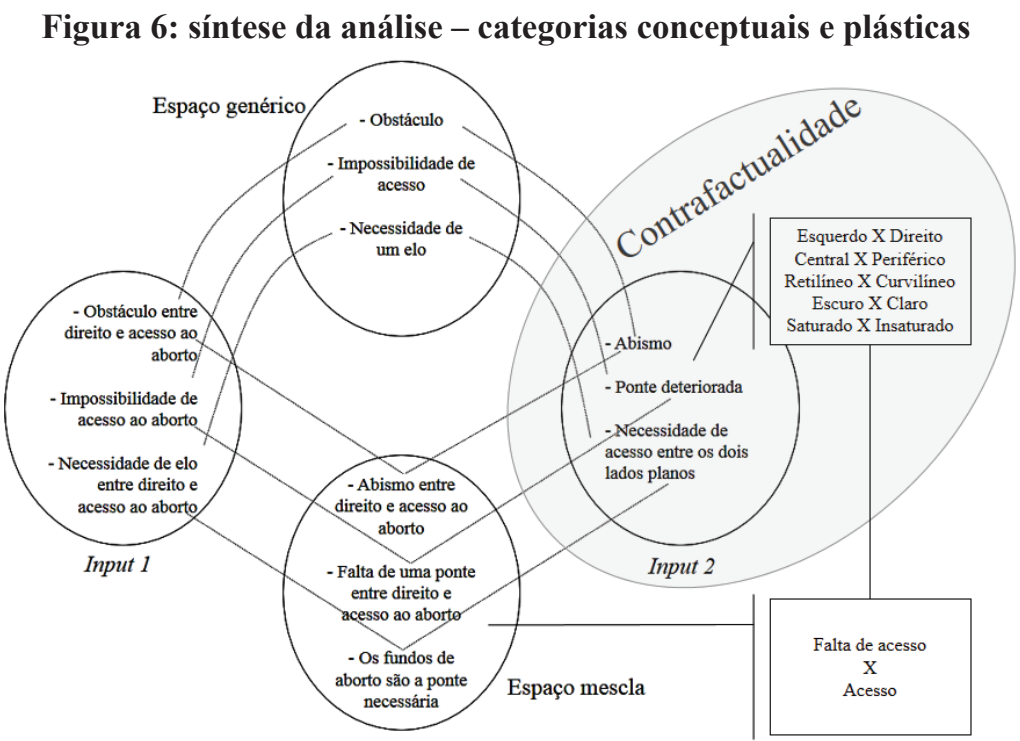

Fonte: elaborada pela autora, 2016.

A seção a seguir traz as considerações finais para o trabalho, incluindo as limitações da pesquisa.

\section{Considerações finais}

O presente trabalho buscou uma aproximação preliminar entre a Teoria da Mesclagem Conceptual e a Semiótica Plástica visual, de modo a analisar um infográfico em todo o seu sincretismo; a análise mostra como essas abordagens podem ser complementares, visto que o aparato das teorias linguístico-cognitivas é comumente aplicado a textos escritos, desconsiderando aspectos visuais ou plásticos. Acreditamos que tenha sido possível enriquecer a descrição das mesclagens conceptuais a partir do emprego das categorias plásticas, dado que a 
própria mesclagem principal do infográfico - entre uma lacuna complexa e uma ravina concreta - dá-se por meio da conjunção entre texto e imagem.

Nesse sentido, o infográfico analisado reforça um dos principais pressupostos da Linguística Cognitiva relativos ao funcionamento das operações cognitivas que incidem sobre a linguagem humana: tendemos a compreender domínios mais abstratos a partir da estrutura de domínios mais concretos (LAKOFF; JOHNSON, 1999). No infográfico, o modo como a mesclagem conceptual desemboca na estrutura da imagem, figurativizando a dificuldade de acesso ao aborto por meio do abismo, é contundente ao revelar como a nossa razão se estrutura em processos imaginativos que primam pelo concreto, pois essa é a base necessária ao desenvolvimento de habilidades que nos permitem agir no mundo. A análise também sugere o fenômeno da contrafactualidade como ponto de convergência entre essas abordagens, permitindo que informações visuais sejam consideradas como possíveis construtoras de espaços contrafactuais em processos de mesclagem.

Por fim, quanto às limitações da pesquisa, reconhecemos o fato de que um estudo de caso isolado não é suficiente para que estabeleçamos generalizações acerca de convergências e distanciamentos - ou "pontes" e "ravinas" - entre a Teoria das Mesclagens Conceptuais e a Semiótica Plástica. Em vista disso, podemos afirmar que essa interface ainda carece de estudos mais aprofundados e sistemáticos, em prol de modelos de análise que privilegiem os sincretismos cognitivos e visuais que permeiam a linguagem humana. 


\title{
Analysis of an Infographic from Conceptual Blending Theory and Greimasian Plastic Semiotics: Interdisciplinarity for Better Understanding a Syncretic Text
}

\begin{abstract}
This paper aims at checking the existence of converging aspects between Conceptual Blending Theory and the Plastic or Visual Semiotics approach, in order to better understand meaning construction in an infographic whose main subject is poor women's shrinking access to legal abortion in the United States. Infographics are herein understood as a syncretic genre that binds visual information with written texts, in order to consolidate an independent communication unit. The applied analysis is overall qualitative, encompassing the identification of emergent conceptual blendings and the validation of visual elements in the infographic that are related to these blendings through topological, eidetic, and chromatic categories. According to the obtained results, it was possible to enrich the description of the conceptual blendings through Greimasian plastic categories, since the blending that structures the infographic is expressed by means of the conjunction between text and image.
\end{abstract}

Keywords: Conceptual Blending Theory. Greimasian Plastic semiotics. Infographic. Multimodality. Abortion.

\section{Referências}

BIRDSELL, B. J. Fauconnier's theory of mental spaces and conceptual blending: LiTTlEMORE, J.; TAYLOR, J. (Orgs.) The Bloomsbury Companion to Cognitive Linguistics. London/New York: Bloomsbury, 2014. p. 72-90.

CARVALHO, J.; ARAGÃO, I. Infografia: conceito e prática. Infodesign. São Paulo, v. 9, n. 3, p.160-177, 2012. Disponível em: <https://infodesign.emnuvens. com.br/infodesign/article/view/136/114>. Acesso em: 14 nov. 2016.

CREPALDE, A. A construção do significado de tekoha pelos Kaiowá do Mato Grosso do Sul. 2014. 266 f. Tese (Doutorado em Letras) - Programa de PósGraduação em Letras, Universidade Federal do Rio Grande do Sul (UFRGS), Porto Alegre, 2014. Disponível em: <http://www.lume.ufrgs.br/bitstream/ handle/10183/115758/000956346.pdf?sequence=1>. Acesso em: 21 out. 2016 .

CRUSE, A. A Glossary of Semantics and Pragmatics. Edinburg: Edinburg University Press, 2006. 
DONDIS, D. A. Sintaxe da linguagem visual. São Paulo: Martins Fontes, 1997. FAUCONNIER, G.; TURNER, M. The Way We Think: Conceptual Blending and The Mind's Hidden Complexities. New York: Basic Books, 2002.

FERNANDES, C. M.; JÜRGENS, S. Transdisciplinary Research Bridging Cognitive Linguistics and Digital Performance: from Multimodal Corpora to Choreographic Knowledge-bases. In: SCHROEDER, F. (Ed.) Performing Technology: User content and the new digital media: insights from the Two Thousand + NINE Symposium. Newcastle: Cambridge Scholars Publishing, 2009. FERREIRA, F. A. R. A corporificação presente nos sinais de libras: uma abordagem da Linguística Cognitiva. Philologus - Supl.: Anais do VI SINEFIL, Rio de Janeiro, v. 20, n. 28, p. 51-60, jan./abr. 2014. Disponível em: <http://www. filologia.org.br/revista/58supl/004.pdf>. Acesso em: 14 nov. 2016.

GAP. In: MERRIAM WEBSTER. Springfield, [2016?]. Disponível em: <http:// www.merriam-webster.com/dictionary/gap>. Acesso em: 14 jul. 2016.

GREIMAS, A. J. Semiótica figurativa e semiótica plástica. In: OLIVEIRA, A. C. (Org.) Semiótica plástica. São Paulo: Hecker Editores, 2004. p. 75-96.

GREIMAS, A. J.; COURTÉS, J. Dicionário de semiótica. São Paulo: Cultrix, 1980.

HART, C. Cognitive Linguistics in Critical Discourse Analysis. Newcastle: Cambridge Scholar Publishing, 2010.

HJELMSLEV, L. Prolegômenos a uma teoria da linguagem. São Paulo: Perspectiva, 1975.

JOHNSON, M. The Body in the Mind. The Bodily Basis of Meaning, Imagination, and Reason. Chicago: The University of Chicago Press, 1987.

KÖVECSES, Z. Language, Mind and Culture. A practical introduction. New York: Oxford University Press, 2006.

LAKOFF, G. Women, Fire and Dangerous Things. What Categories Reveal About Mind. Chicago: The University of Chicago Press, 1990.

LAKOFF, G.; JOHNSON, M. Metaphors We Live By. Chicago: The University of Chicago Press, 1980.

LAKOFF, G.; JOHNSON, M. Philosophy in the Flesh. The Embodied Mind and its Challenge to Western Thought. New York: Basic Books, 1999. 
MORATO, E. F. Do conteúdo à expressão: uma análise semiótica dos textos pictóricos de Mestre Ataíde. 2008. 117 f. Dissertação (Mestrado em Estudos Linguísticos). Programa de Pós-Graduação em Estudos Linguísticos da Faculdade de Letras, Universidade Federal de Minas Gerais (UFMG), Belo Horizonte, 2008. Disponível em: $<$ http://www.bibliotecadigital.ufmg.br/dspace/handle/1843/ AIRR-7DHPX5>. Acesso em: 14 nov. 2016.

NATIONAL NETWORK OF ABORTION FUNDS. Mind the Gap: Infographic. Boston, 2013. Disponível em: < https://fundabortionnow.org/downloads/mindgap-infographic>. Acesso em: 14 jul. 2016.

NOTH, W. A semiótica no século XX. São Paulo: ANNABLUME, 1996.

OLIVEIRA, A. C. (Org.) Semiótica plástica. São Paulo: Hecker Editores, 2004.

PIETROFORTE, A. Análise do texto visual: a construção da imagem. São Paulo: Contexto, 2007.

PIETROFORTE, A. Semiótica visual: percursos do olhar. São Paulo: Contexto, 2004.

PIASSI, L. P. C. Interfaces entre Fantasia e Ciência: um estudo semiótico do filme "2001: Uma odisseia no espaço" como modelo de interpretação em perspectiva educacional. Tese de livre docência. Universidade de São Paulo (USP): São Paulo, 2012.

PINTO, R. Como argumentar e persuadir? Práticas: política, jurídica e jornalística. Lisboa: Quid Juris, 2010.

SALOMÃO, M. M. Teorias da linguagem: a perspectiva sociocognitiva. In: MIRANDA, N. S.; SAlOMÃO, M. M. (Org.) Construções do Português do Brasil: da gramática ao discurso. Belo Horizonte: UFMG, 2009.

SANTOS, A. N. Direito, aborto e anencefalia no Brasil: uma abordagem semântico-cognitiva da ADPF 54. Dissertação de mestrado. Universidade do Vale do Rio dos Sinos (Unisinos): São Leopoldo, 2016.

SEGUNDO, P. R. G. Convergências entre a Análise Crítica do Discurso e a Linguística Cognitiva: Integração Conceptual, Metáfora e Dinâmica de Forças. Veredas, Juiz de Fora, v. 8, n. 2, p. 32-50, 2014. Disponível em: <http://www.ufjf. br/revistaveredas/files/2015/04/3-SEGUNDO1.pdf $>$. Acesso em: 14 jul. 2016.

SOUZA, J. A. C. O infográfico e a Divulgação Científica Midiática (DCM): (entre)texto e discurso. 2012. 306 f. Tese (Doutorado em Linguística Aplicada) Programa de Pós-Graduação em Linguística Aplicada, Universidade do Vale do 
Rio dos Sinos (Unisinos), São Leopoldo, 2012. Disponível em: <http://biblioteca. asav.org.br/vinculos/000001/00000118.pdf>. Acesso em: 14 jul. 2016.

TURNER, M. Conceptual integration. In: GEERAERTS, D.; CUYCKENS, H. The Oxford Handbook of Cognitive Linguistics. New York: Oxford University Press, 2007.

ZIEM, A. Frames of understanding in Text and Discourse. Amsterdam: John Benjamins, 2014. 